\title{
ANÁLISE DAS PRÁTICAS PEDAGÓGICAS DE VARIAÇÃO LINGUÍSTICA NO \\ ENSINO FUNDAMENTAL II
}

\author{
Laís Lagreca de Carvalho ${ }^{1}$ \\ Flaviane Gonçalves Corrêa ${ }^{2}$
}

Resumo: Neste artigo, buscamos apresentar algumas reflexões relacionadas ao ensino de Língua Portuguesa no oitavo ano do Ensino Fundamental em uma Escola Estadual localizada na região oeste da cidade de Juiz de Fora - MG. Tomamos como referência as aulas, acompanhadas durante o Estágio Supervisionado I de Língua Portuguesa, voltadas para o trabalho com a variação linguística. Dessa forma, com base na observação do planejamento das aulas e na mediação do professor no trabalho de conscientização sobre a variação linguística, percebemos que a escolha do material utilizado nas aulas e o reconhecimento do conhecimento de mundo do aluno são peças fundamentais para a construção da consciência linguística dos discentes, a qual transpassa os muros da escola, pois contribui para a formação cidadã dos alunos.

Palavras-chave: Análise de prática pedagógica. Conscientização linguística. Ensino de língua portuguesa. Ensino fundamental II. Variação linguística.

\section{Introdução}

O presente artigo é fruto das observações e da análise das aulas de uma professora de Língua Portuguesa do oitavo ano do Ensino Fundamental de uma Escola Estadual, situada na região oeste da cidade de Juiz de Fora - MG. Essas aulas foram acompanhadas durante o Estágio Supervisionado I de Língua Portuguesa, do curso de Letras da Universidade Federal de Juiz de Fora.

No decorrer do estágio, observamos as estratégias utilizadas pela docente no trabalho com os alunos de conscientização sobre a variação linguística. Tais estratégias envolveram o planejamento de suas aulas e a mediação pedagógica, que visavam a conscientização por parte dos alunos sobre a variação linguística.

Dessa forma, este trabalho traz discussões a respeito da importância de tratar na escola a variação linguística, essas discussões vão ao encontro do que sugere Faraco (s.d.):

[...] cabe reiterar que nosso grande desafio, [...] é reunir esforços para construir uma pedagogia da variação linguística que não escamoteie a realidade linguística do país (reconheça-o como multilíngue e dê destaque

\footnotetext{
${ }^{1}$ Mestranda em Linguística na Universidade Federal de Juiz de Fora - laislagreca@gmail.com

${ }^{2}$ Graduada em Letras na Universidade Federal de Juiz de Fora - flavianegcorrea@gmail.com
}

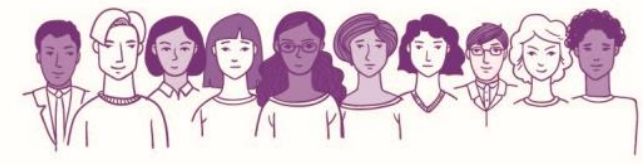


crítico à variação social do português); não dê um tratamento anedótico ou estereotipado aos fenômenos da variação; localize adequadamente os fatos da norma culta no quadro amplo da variação e no contexto das práticas sociais que a pressupõem; abandone criticamente a cultivo da norma-padrão; estimule a percepção do potencial estilístico e retórico dos fenômenos da variação. (FARACO, s.d.: 9)

Sendo assim, primeiramente, faremos uma contextualização do espaço escolar, para, em seguida, apresentarmos a fundamentação teórica que embasa nossas discussões. Posteriormente, com base em um recorte de algumas aulas ministradas pela professora responsável pela turma, faremos a descrição e a análise das experiências observadas.

\section{A escola}

A escola em que o estágio se desenvolveu foi fundada no ano de 2009, é uma instituição de ensino estadual, vinculada à Secretaria de Educação de Minas Gerais, localizada na região oeste da cidade de Juiz de Fora, Minas Gerais.

Atualmente, a escola ministra cursos de Ensino Fundamental, Ensino Médio e Educação de Jovens e Adultos (EJA). Por estar localizada nas proximidades da Universidade Federal de Juiz de Fora, essa instituição recebe grande número de estagiários de diferentes cursos de licenciatura oferecidos pela UFJF.

A escola é a única dessa região a oferecer Ensino Médio, fazendo com que receba alunos de bairros vizinhos. O ingresso na escola é realizado através da matrícula feita pelos pais ou responsáveis.

\section{A turma}

A turma acompanhada durante o Estágio Supervisionado I de Língua Portuguesa é composta por um total de 37 alunos e a carga horária da disciplina de Português é de 6h/aula por semana, em horário vespertino. Os alunos têm durante o ano quatro bimestres, os dois primeiros valem 20 pontos, e os dois últimos, trinta. A média para ser aprovado é de 60 pontos no final do ano.

Os discentes possuem faixa etária entre 13 e 15 anos. Eles são bastante falantes, característica que requer uma vigilância maior por parte da professora para que não percam o

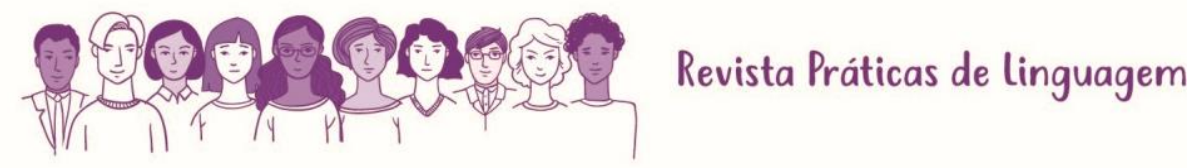


foco, porém, ainda que possam ter sua atenção dispersada com facilidade, não deixam de ser participativos.

É possível perceber que os alunos têm afinidades e se relacionam bem, esse entrosamento talvez se deva ao fato de muitos se conhecerem desde os anos iniciais do ensino fundamental ou por morarem próximos uns aos outros.

Na próxima seção será apresentado o arcabouço teórico que sustenta nossas discussões, para que, em seguida, realizemos a descrição e a análise das aulas observadas.

\section{Pressupostos teóricos}

Segundo Bortoni-Ricardo (2009), os três ambientes onde a criança começa a desenvolver o seu processo de sociabilização são no ambiente familiar, no ambiente entre amigos e no ambiente escolar. Tais ambientes podem ser chamados, de acordo com a tradição sociológica, de domínios sociais.

O domínio social é um espaço físico onde ocorre a interação dos sujeitos, sendo que tais sujeitos assumem determinados papéis sociais. Os papéis sociais são obrigações e direitos definidos por normas socioculturais, que decorrem da relação humana. Ao usarmos a linguagem para nos comunicar, também estamos concebendo e fortalecendo os papéis sociais específicos de cada domínio.

É comum observamos que alguns alunos têm dificuldades, justamente, na transição do domínio familiar para o domínio da escola, isso pode acontecer por ser a transição de uma cultura predominante oral para uma cultura predominante escrita. O aluno precisa tomar ciência, em algum momento, que a escrita não reflete a fala individual de ninguém e de nenhum grupo social especificamente. Dessa forma, a fala e a escrita exigem conhecimentos diferentes. Como há variação na forma como as pessoas falam, por diversos fatores, houve a necessidade de uma norma-padrão escrita. Por esse motivo, existe o Vocabulário Ortográfico, de responsabilidade da Academia Brasileira de Letras. Se pensarmos que a norma-padrão escrita imposta a nós nos dias de hoje é aquela estabelecida no século XIX, é possível entender a dificuldade dos alunos.

Na sala de aula, como em qualquer outro domínio social, é possível observar uma vasta variação no uso da língua, mesmo na forma como a professora fala que, por representar certa ascendência sobre seus alunos, está sujeitada a regras mais rigorosas no seu comportamento verbal e não verbal. Concluímos que em todas as esferas submetidas aos domínios sociais há

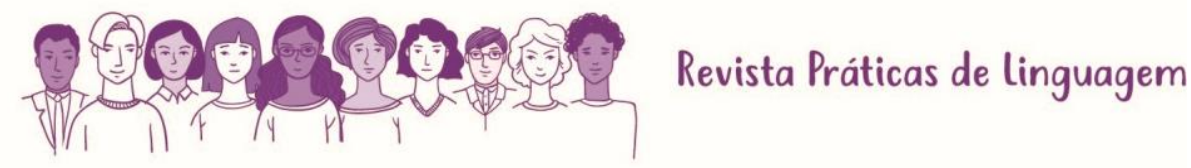


regras que determinam as ações que ali são realizadas. O nível dessa variação pode ser maior ou menor em alguns domínios. Tomemos como exemplo o domínio familiar ou as atividades de lazer, nesses domínios é possível notar mais variação linguística do que no domínio escolar. Porém, em todos os domínios há variação, pois a variação é dependente da própria comunidade linguística.

De acordo com Bortoni-Ricardo

\begin{abstract}
Se um professor do Ensino Básico conhece as características da fala do grupo social de onde provêm seus alunos, poderá planejar seu trabalho pedagógico com vistas a ampliar a competência comunicativa desses alunos, habilitandoos a usar outras variantes de mais prestígio, na escrita e na fala quando essa precisa ser monitorada. Todo falante tem de monitorar sua fala de modo a atender às expectativas de seus ouvintes; tal flexibilidade é fundamental para que ele possa ser bem recebido em qualquer ambiente e assim ter mobilidade social. (BORTONI-RICARDO, 2011:2)
\end{abstract}

Não só os professores como também todos os envolvidos no espaço escolar - diretores, coordenadores etc. - tendem a ter uma linguagem mais planejada que a dos alunos, sendo possível chamá-la de linguagem monitorada. Também os eventos realizados no espaço escolar tendem a ser mais ou menos monitorados, eventos de sala de aula tendem a ser mais formais que eventos que ocorrem na cantina ou no recreio.

Porém, "o grau de monitoração que um falante pode conferir a sua fala vai depender dos recursos comunicativos que ele já adquiriu, no contato com a língua escrita e com eventos monitorados de linguagem oral" (BORTONI-RICARDO, 2009:29). O sujeito, independentemente da posição que ocupa no espaço escolar, só consegue monitorar sua fala a partir do seu repertório linguístico. Sendo assim, para o aluno, esse monitoramento pode ser uma tarefa mais difícil, pois seu reportório linguístico é mais limitado, o que contribui para que cometa mais "erros de português".

De acordo com a autora,

Erros de português são simplesmente diferenças entre variedades da língua. Com frequência, essas diferenças se apresentam entre a variedade usada no domínio do lar, onde predomina uma cultura de oralidade, em relações permeadas pelo afeto e informalidade [...], e culturas de letramento, como a que é cultivada na escola. (BORTONI-RICARDO, 2009:37)

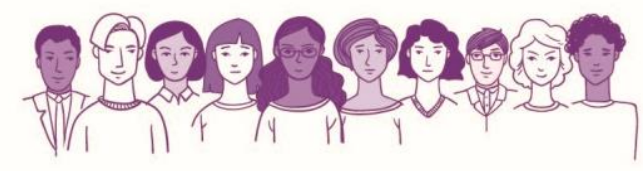


As variedades se sobrepõem quando o professor intervém, fornecendo a variante padrão, ao flagrar o aluno usando uma regra não padrão para determinado contexto. Isso não significa que o professor deva expor o aluno diante da turma, caso identifique o uso da regra não padrão, ele pode não intervir abruptamente, mas esperar que o aluno conclua sua ideia para que, então, apresente o modelo da variante padrão.

Dessa forma, a estratégia do professor deve incluir dois componentes: a identificação da diferença e a conscientização da diferença. A identificação pode ficar comprometida se o professor não atentar ou desconhecer aquela regra. No geral, os professores são os principais agentes letrados, conseguem identificar estruturas linguísticas com as quais seus alunos poderão sentir dificuldades, antecipando-as, e associando-as às variantes mais usuais dos alunos.

O outro item - a conscientização - é mais árduo. $O$ aluno precisa ser conscientizado das diferenças para que possa começar a monitorar seu próprio estilo, mas tal conscientização não pode prejudicar o processo de ensino/aprendizagem. Muitas vezes é melhor retardar uma intervenção para que uma ideia não se fragmente, ou um raciocínio não se interrompa. Primordialmente, é preciso manifestar o devido respeito às características culturais e psicológicas do aluno. A conduta inapropriada ou até mesmo desrespeitosa das diferenças pode gerar insegurança, desinteresse ou revolta.

A língua padrão é uma variedade linguística, vista por muito tempo, como um ideal a ser atingido pelos falantes, que, através das variantes, acabam se distanciando, cada vez mais, desse "objeto inatingível". Desse modo, o objetivo de toda essa força-tarefa seria, segundo Faraco, "[...] acima de tudo, uma pedagogia que sensibilize as crianças e os jovens para a variação de tal modo que possamos combater os estigmas linguísticos, a violência simbólica, as exclusões sociais e culturais fundadas na diferença linguística" (FARACO, s.d.: 10).

Concluído o percurso realizado até aqui em relação ao ensino de Língua Portuguesa, à concepção sociolinguística educacional e ao modo como esta concebe a fala e a escrita, apresentaremos, na seção seguinte, a descrição das aulas observadas durante o Estágio Supervisionado I de Língua Portuguesa para, em seguida, apresentar a análise realizada dessas aulas. 


\section{Descrição das atividades}

O Estágio Supervisionado I de Língua Portuguesa possibilitou o acompanhamento de um total de trinta e seis horas/aula. No entanto, a fim de realizar reflexões sobre a prática pedagógica do trabalho com variação linguística na sala de aula, fizemos um recorte de um bloco de aulas cujo foco era a conscientização por parte dos alunos de que nós não falamos como escrevemos. Desse modo, realizaremos a seguir a descrição das atividades observadas.

Em um primeiro momento, a professora levantou a seguinte questão para os alunos: "Nós falamos da mesma maneira como escrevemos?", a essa pergunta foram dadas algumas repostas, como "Não, porque a gente fala errado."; "Não, porque a gente pensa menos pra falar do que pra escrever."; "A gente fala e escreve da mesma forma.". Ao ouvir as respostas da turma, a professora colocou a palavra "tomate" no quadro e perguntou como nós a pronunciamos, fazendo com que os alunos que haviam pensado que falamos e escrevemos da mesma forma ficassem desconcertados e, através da fala de seus colegas e de sua própria reflexão, concluíssem que, de fato, nós não falamos da mesma forma como escrevemos. Após esse momento de reflexão conjunta, a professora revelou para turma que, realmente, nós não falamos da mesma maneira que escrevemos, porque a escrita é mais planejada e a fala, por sua vez, é mais espontânea.

Para dar continuidade a essa reflexão sobre fala e escrita, a professora colocou a seguinte sentença no quadro: "Os meninos bonitos compraram um litro de leite e três potes de massa de tomate" e, em seguida, pediu que os alunos a reescrevessem da maneira como se fala. A realização dessa atividade foi muito interessante, pois foi possível perceber que muitos já têm uma consciência com relação à pronúncia e, além disso, durante a elaboração da atividade, os alunos demonstraram possuir tanto um conhecimento fonológico como um conhecimento de variação diatópica ${ }^{3}$, tendo em vista que questionavam à professora a maneira como pessoas de outras regiões falam, um desses questionamentos, por exemplo, foi o modo como os cariocas falam o "s" em final de palavra ou de sílaba.

Com base nesses questionamentos, a professora falou sobre as diferenças marcantes na fala de pessoas de diferentes regiões do Brasil (os alunos adoraram essa parte, pois eles

\footnotetext{
${ }^{3}$ Coelho et al. (2015:38) denomina que a variação diatópica, também conhecida por variação regional, ou ainda variação geográfica, é a variação responsável por podermos identificar a origem de uma pessoa pelo modo como ela fala. Em geral, itens lexicais particulares, certos padrões entoacionais e certos traços fonológicos respondem pelo fato de que falantes de localidades distintas apresentem dialetos (ou seja, variedades) diferentes de uma mesma língua.
}

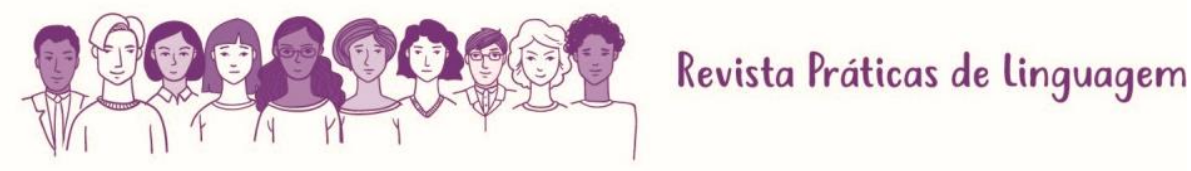


reconheciam essas marcas) e, depois, colocou no quadro a sentença reescrita da forma como é falada (baseando-se, principalmente, na fala mineira): "us mininu bunitu compraram um li dji leitchi i três potchi di mastumatchi". A professora falou com os alunos que "compraram" também poderia estar escrito como "comprô" e, depois, pediu que eles fizessem a mesma tarefa com a sentença "As amigas do Juninho acordam tarde e só bebem leite quente". Após ter sido dado um tempo para que os alunos realizassem a reescrita, a professora, ouvindo a resposta dos alunos, formulou no quadro a reposta, que ficou assim: "azamiga du junin acorda tardji i só bebe leitchi quentchi". Com essa sentença, foi possível perceber que os alunos entendem que, na pronúncia, nós unimos palavras como "azamiga", e, além disso, que uma consoante como o "s", quando está entre duas vogais, mesmo que em fronteira de palavras, passa ao som de " $\mathrm{z}$ ".

Após esse primeiro momento de reflexão sobre fala vs. escrita, a professora fez a seguinte pergunta aos alunos: "O que aconteceria se nós escrevêssemos exatamente como falamos?". Os alunos responderam, quase que de imediato, que seria muito difícil de nos entendermos, e a professora concordou com eles e foi acrescentando questões como "imagina, se uma pessoa lá no Norte escrevesse como fala, uma pessoa no Sul, outra no Nordeste. Além disso, até mesmo aqui em Minas Gerais, não falamos todos da mesma forma, não é? As mulheres têm um jeito de falar que, em alguns casos, se diferencia do jeito com que os homens falam, não é?". Com esses questionamentos, os alunos foram percebendo a variação linguística além das questões geográficas, mas, também, as variações de gênero, e a professora pôde entrar em um ponto chave da reflexão: o papel da "língua padrão", demonstrando que é preciso haver um padrão para que todos possam se entender, caso contrário, cada um iria reproduzir na escrita a sua própria maneira de falar, o que geraria um problema de comunicação. Adicionalmente, a professora chamou a atenção dos alunos para as noções de "certo" e "errado", pois alguns alunos, quando questionados se falam da mesma forma como escrevem, disseram que falavam "errado", e demonstrou-lhes que não é adequado falarmos que alguém fala "errado" ou "certo", mas que, de acordo com o contexto em que a pessoa se encontra, ela deveria falar/escrever de acordo com a norma-padrão ${ }^{4}$ e, caso isso não ocorra, a pessoa não estará falando "errado", mas estará desviando-se do "padrão".

Ao serem realizados esses primeiros momentos - questionamento e reflexão - a professora levou os alunos para sala de vídeo, onde eles puderam assistir ao clip da música

\footnotetext{
${ }^{4}$ Faraco (s.d.: 5) denomina: “a norma-padrão [...] é um construto idealizado (não é um 'dialeto' ou um conjunto de 'dialetos', como é a norma culta, mas uma codificação taxonômica de formas assumidas como um modelo linguístico ideal).".
}

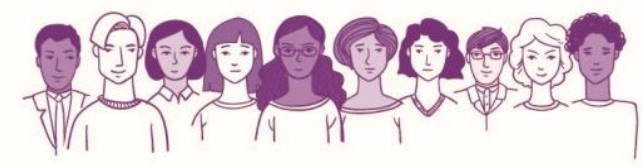


"Subirusdoistiozin" do cantor Criolo. Após assistir ao vídeo, a professora entregou a letra da música (ANEXO I), permitindo que os alunos vissem, na escrita, a linguagem da música, que é marcada por expressões da oralidade, como as gírias, além de trazer as palavras escritas como, geralmente, as pessoas falam informalmente, sem colocar o " $r$ " em palavras como "falar" > "falá", e expressões utilizadas por determinados grupos, o que pode fazer com que nem todos entendam determinadas expressões, como “... pra bater de front, e o Babylon cair...". Ainda na sala de vídeo, a professora discutiu com os alunos sobre o sentido da música, falando que se tratava de um rap, estilo musical que tem como uma de suas características denunciar os problemas sociais, como os que acontecem em favelas, sendo, portanto, uma música de identidade cultural.

Ao voltar para a sala de aula, a professora pediu que os alunos destacassem as marcas de oralidade contidas na letra da música. Quando todos terminaram a atividade, a professora conferiu com a turma quais eram as marcas de oralidade presentes no texto e, conforme a correção se desenvolvia, ela questionava o sentido de cada termo destacado e, com base na resposta dos alunos, explicava o que queria dizer cada um desses termos.

Ao terminar essa atividade, a professora propôs que a turma se dividisse em grupos para que cada conjunto de alunos elaborasse um "dicionário de gírias" com o maior número possível de palavras. Essa atividade foi muito interessante, pois, quando os alunos buscavam em seus conhecimentos palavras que pudessem ser categorizadas como gírias, para saber se, de fato, uma palavra era ou não uma gíria, eles analisavam o contexto em que a usariam, o que nos mostrou que eles percebiam que a gíria estava ligada a um contexto menos formal de uso da língua. Só pelo fato de a professora ter dividido a turma em grupos, os alunos se sentiram em uma espécie de competição e quiseram encontrar o maior número de gírias que pudessem.

Ainda como parte do trabalho com a variação linguística, a professora trouxe para os alunos uma reportagem escrita por Alfredina Nery (Anexo II) intitulada "Não se fala como se escreve" e, a partir da seguinte afirmação presente no início do texto: "Português é fácil de aprender porque é uma língua que se escreve exatamente como se fala.", questionou aos alunos se era assim mesmo que eles viam a Língua Portuguesa e o que eles pensavam a respeito. Depois, continuou a leitura, chamando a atenção para o comentário, presente no texto, do humorista Jô Soares, de modo a questionar o tom irônico com o qual Jô Soares escreveu, um ponto que chamou a atenção dos alunos, já que não falamos da mesma forma que escrevemos.

Ao realizar a leitura do texto por completo, a professora chama a atenção para o trecho do poema de Antônio Sales, "Malinculia", presente na reportagem, e pede que os alunos o

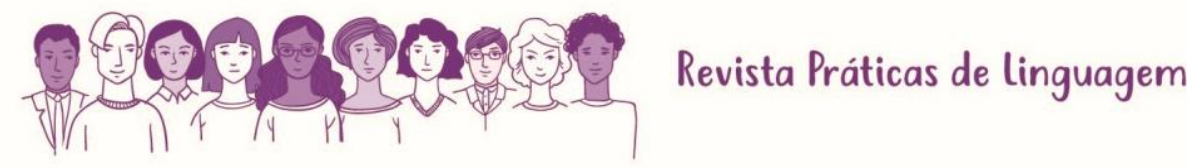


reescrevam utilizando a norma-padrão do Português. Tendo sido feita a reescrita, a professora questionou aos alunos sobre o eu lírico do poema (para isso ela retomou o conceito de "eu lírico"), e eles comentaram que parecia ser uma pessoa que vivia no interior. Em seguida, a professora lhes pergunta se o eu lírico domina a norma-padrão e os alunos respondem que, de acordo com o texto, parece que não. A professora, então, fala com os alunos que a maneira como esse poema foi escrito tem um propósito, mostrando que não foi aleatoriamente que se deu essa escolha, e que, ao reescrevermos o texto, acabamos com sua expressividade, tendo em vista que descaracterizamos o eu lírico, que ficou sem a sua identidade.

Ao final dessas atividades reflexivas, os alunos estavam conscientes de que nós não falamos da mesma forma como escrevemos e o porquê disso. Ademais, na construção desse conhecimento, a professora pôde discutir com eles diversos fatores que perpassam a variação linguística e, consequentemente, questões sobre preconceito linguístico puderam ser trabalhadas, fazendo com que os alunos deixassem de ver o uso da língua portuguesa a partir da dicotomia "certo" e "errado".

\section{Análise}

Acreditamos que o professor de língua materna deve refletir sobre a relação intrínseca entre o indivíduo e a língua, entre o meio em que o indivíduo se encontra e a língua, fazendo com que sejam potencializados os conhecimentos que os alunos já possuem da própria língua. Portanto, é preciso que o docente busque mostrar aos alunos como a língua acontece, isto é, como é o funcionamento da língua, de maneira que eles possam compreender e dominar esse mecanismo.

Assim, ao trabalhar a conscientização linguística em sala de aula, o docente proporciona uma reflexão que coloca os alunos como pertencentes ao objeto de estudo, ou seja, os alunos passam a refletir sobre o uso que eles próprios fazem da língua, percebendo que a língua está presente em todos os momentos de nossas vidas.

Ao partir do questionamento sobre a fala e a escrita, com relação a maneira como exercemos cada uma delas, o docente coloca em evidência que para exercer cada uma dessas ações, falar e escrever, precisamos lançar mão de conhecimentos específicos, relacionados ao contexto em que o usuário da língua se encontra e à intenção de determinada produção. Ademais, ao expor as diferenças presentes no falar de pessoas de diferentes lugares, o professor ganha espaço para trabalhar com a quebra de estigmas criados pela sociedade, que, muitas

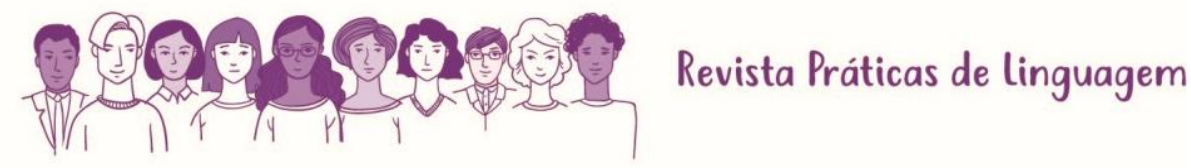


vezes, passa adiante a ideia de que existe um falar melhor que o outro (ideia muitas vezes reforçada pelos estereótipos presentes nas novelas, e pela fala "livre" de sotaque dos jornalistas, por exemplo).

Ao mostrar para os alunos o quão rica é a língua e as inúmeras características que a compõem, o professor consegue demonstrar a importância de haver uma forma padronizada para a escrita. À medida que os alunos percebem e reconhecem a variação linguística, problematizam a ideia de cada um escrever à sua maneira, pois concordam que é necessário haver um padrão que permita o entendimento de pessoas que estão, ainda que em um mesmo país, muito distantes geograficamente.

É papel do professor de Língua Portuguesa conscientizar os alunos a respeito da variação linguística, mas, para que esse trabalho seja bem sucedido, é imprescindível que o docente saiba reconhecer o repertório linguístico do aluno, levando em consideração a possibilidade, quase certa, de o aluno cometer os chamados "erros de português" por utilizar a variedade linguística usada em sua casa, onde a informalidade prevalece. Esse reconhecimento por parte do professor deve estar relacionado ao respeito à expressão do aluno, o que não anula o papel do docente de inserir os alunos nessa outra cultura e letrá-los para as situações com as quais eles ainda não tiveram contato e, muito provavelmente, virão a ter.

Foi possível perceber que a professora se preocupou em deixar que os alunos identificassem as diferenças presentes na forma como falamos e como escrevemos para, somente depois, levá-los à conscientização sobre essa diferença. Ao perceber as diferenças desses dois tipos de produção (oral e escrita), os alunos começaram a refletir, ainda que não dissessem com essas palavras, sobre o monitoramento linguístico, que na escrita é maior.

Por mais que as aulas tenham sido voltadas para a diferença entre fala e escrita, ao tratar desses dois tipos de produção, a professora pôde promover a reflexão da variação linguística de modo geral, alcançando a discussão sobre o preconceito linguístico, o que vai ao encontro das ideias de (FARACO, s.d.) que fala sobre a importância de se desenvolver uma pedagogia preocupada em sensibilizar os alunos sobre a variação, colaborando para o combate aos estigmas linguísticos. 
Considerações finais

O artigo buscou apresentar algumas reflexões relacionadas ao ensino de Língua Portuguesa no que se refere ao tratamento da variação linguística em sala de aula, mais especificamente no Ensino Fundamental 2.

Dessa maneira, as análises dos dados demonstram, em relação ao trabalho sobre a variação linguística, a fundamental importância de o professor reconhecer o meio do qual o aluno vem, pois as práticas linguísticas de um contexto majoritariamente oral, como o lar, podem ser transferidas para a escola, onde o aluno aprimora suas práticas letradas e adquire outras.

Além disso, foi possível perceber que, ao trabalhar um tema como a variação linguística, é preciso deixar que o aluno exponha o conhecimento que traz de mundo, de modo que se sinta um participante ativo na construção desse conhecimento, já que, de fato, o é, pois faz uso da língua, o objeto analisado, a todo instante.

Outro ponto chave é a escolha do material com o qual se desenvolverá o trabalho, nesse sentido, a escolha da letra de música, um rap, merece destaque, pois os alunos se identificaram com o estilo musical e perceberam que, naquele contexto, o uso de gírias e expressões utilizadas na oralidade era apropriado, já que condizia com a mensagem da música.

Levar o aluno a reconhecer e respeitar as diferentes formas de usar a língua vai além do conteúdo da disciplina, tendo em vista que abarca o respeito mútuo e contribui tanto para o aperfeiçoamento das diferentes práticas letradas já conhecidas quanto para a inserção em novas práticas com as quais ele poderá se deparar, ou seja, mostrar o respeito às diferentes formas de falar faz parte do compromisso da escola de formar cidadãos críticos e capazes de interagir na sociedade.

\title{
ANALYSIS OF THE PEDAGOGICAL PRACTICES OF LANGUAGE VARIATION IN ELEMENTARY SCHOOL
}

\begin{abstract}
In this paper, we present reflections related to the teaching of Portuguese Language in the eighth year of Elementary School in a State School located in the western region of the city of Juiz de Fora - MG. We take as reference the classes, accompanied during the Supervised Internship I of Portuguese Language, focused on the work with linguistic variation. Thus, based on the observation of lesson planning and teacher mediation in the work of raising awareness about linguistic variation, we noticed that the choice of the material used in the classes and the recognition of the student's world knowledge are fundamental pieces for the construction of the students' linguistic awareness, which transcends the walls of the school, as it contributes to the students' citizenship.
\end{abstract}

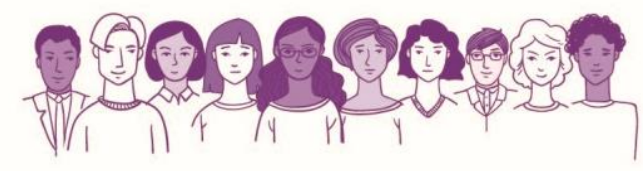


Keywords: Analysis of pedagogical practice. Linguistic awareness. Teaching of Portuguese language. Elementary education II. Linguistic variation.

\section{Referências}

BORTONI-RICARDO, Stella Maris. Educação em língua materna: a sociolinguística em sala de aula. 6 ed. São Paulo: Parábola, 2009.

Por que ensinar variação linguística em sala de aula? 2011.

COELHO, Izete Lehmkuhl. Para conhecer Sociolinguística. São Paulo: Contexto, 2015.

CYRANKA, Lúcia Furtado de Mendonça; PINTO, Consuelo Domenici Mozzer. Aportes sociolinguísticos à prática do professor - implicações na sala de aula. Cadernos do CNLF, Vol. XIV, №2, t.1. Rio de Janeiro, 2010.

FARACO, Carlos Alberto. Por uma pedagogia da variação linguística. Paraná, s.d. 
Anexo I

\section{Subirusdoistiozin}

(Criolo)

(Tem uns menino bom novo hoje aí na rua, pra lá e pra cá, que corre pelo certo..

Mas já tem uns também que eu vou te falar, viu.. só por Deus, viu! Ave Maria!)

Mandei falá, pra não arrastá, não botaram fé, subirusdoistiozin

O baguio é loco, o sol tá de rachá, vários de campana aqui na do campin

Má quem quer pretá, má quem qué branca, todo azulê requer seu rejuntin

Pleno domingão, flango ou macalão, se o negócio é bão, cê fica é chineizin

Cença aqui patrão, aqui é a lei do cão, quem sorri por aqui, quer ver tu cair

É, é... justo é Deus, o homem não, ouse me julgá, tente a sorte fi.

Para pa pa, para pa pa, para pa pa, para para papa $(4 x)$

Só função no doze, na garagem um Golf, bonitão na praia de Hornet, fi

Tudo isso tem, e o apetite vai, pra bater de front, e Babylon cair

As criança daqui, tão de HK, leva no sarau, salva essa alma aí

Os perreco vem, os perreco vão, as vadia quer, mas nunca vão subir

Cença aqui patrão, eu cresci no mundão, onde o filho chora e a mãe não vê

E covarde são, quem tem tudo de bom, e fornece o mal, pra favela morrer

Uns acham que são, mas nunca vão ser

Feio é arrastar e nem perceber

Para pa pa, para pa pa, para pa pa, para para papa $(4 x)$

Só função no doze, na garagem um Golf, bonitão na praia de Hornet, fi

É, tudo isso tem e o apetite vai, pra bater de from e Babylon cair

As criança daqui, tão de HK, leva no sarau, salva essa alma aí 
Os perreco vem, os perreco vão, as vadia quer, mas nunca vão subir Licença aqui patrão, eu cresci no mundão, onde o filho chora e a mãe não vê E covarde são, quem tem tudo de bom, e fornece o mal, pra favela morrer

(Acostumado com sucrilhos no prato, né, moleque?)

(Enquanto o colarinho branco dá o golpe no Estado)

Disponível em: <https://www.google.com.br/?ion=1\&espv=2\#q=letra\%20de\%20subirusdoistiozin>

\section{Anexo II}

\section{Não se fala como se escreve (Alfredina Nery)}

"Português é fácil de aprender porque é uma língua que se escreve exatamente como se fala."

Pois é. U purtuguêis é muinto fáciu di aprender, purqui é uma língua qui a genti iscrevi ixatamenti cumu si fala. Num é cumu inglêis qui dá até vontadi di ri quandu a genti discobri cumu é qui si iscrevi algumas palavras. Im purtuguêis não. É só prestátenção. U alemão pur exemplu. Qué coisa mais doida? Num bate nada cum nada. Até nu espanhol qui é parecidu, si iscrevi muinto diferenti. Qui bom qui a minha língua é u purtuguêis. Quem soubé falá sabi iscrevê.

O comentário é do humorista Jô Soares, para a revista Veja. Ele brinca com a diferença entre o português falado e escrito. Na verdade, em todas as línguas, as pessoas falam de um jeito e escrevem de outro. A fala e a escrita são duas modalidades diferentes da língua e é com esse fato que o Jô brincou.

Na língua escrita há mais exigências, em relação às regras da gramática normativa. Isso acontece porque, ao falar, as pessoas podem ainda recorrer a outros recursos para que a comunicação ocorra - pode-se pedir que se repita o que foi dito, há os gestos, etc. Já na linguagem escrita, a interação é mais complicada, o que torna necessário assegurar que o texto escrito dê conta da comunicação.

A escrita não reflete a fala individual de ninguém e de nenhum grupo social. Por essa razão, a fala e a escrita exigem conhecimentos diferentes. A maioria de nós, brasileiros, falamos, por 
exemplo, "Eli me ensinô". O português na variante padrão exige, no entanto, que se escreva assim: "Ele me ensinou". Essas diferenças geram muitos conflitos.

A leitura de um trecho do poema de Antonino Sales, "Malinculia", mostra as interferências da fala na escrita e como elas não anulam a expressividade poética de suas imagens.

Malinculia, Patrão, É um suspiro maguado Qui nace no coração! É o grito safucado Duma sodade iscundida Qui nos fala do passado Sem se torná cunhicida! É aquilo qui se sente Sem se pudê ispricá! Qui fala dentro da gente Mas qui não diz onde istá! (...) A língua muda, ainda, conforme o grupo social, a região, e o contexto histórico. São as chamadas variações linguísticas. A gíria e o jargão são algumas dessas variações.

Disponível em: <http://educacao.uol.com.br/disciplinas/portugues/lingua-escrita-e-oral-nao-se-fala-como-se-escreve.htm>. 